\title{
INCREASED LANGUAGE CO-ACTIVATION LEADS TO ENHANCED CROSS-LINGUISTIC PHONETIC CONVERGENCE
}

\begin{abstract}
Purpose: This study investigates the effects of bilingual language modes (or settings) on the speech production patterns of a group of early Catalan/Spanish bilinguals from Majorca, Spain. Our main research question was as follows: Are bilingual speech patterns modulated by the level of (co-)activation of a bilingual's two languages? Design: Bilingual participants were classified as a function of their linguistic experience (or dominance), from Catalan- to Spanish-dominant. Subsequently, we recorded their speech in two experimental settings: a unilingual setting in which only Catalan words were uttered, and a bilingual setting in which both Catalan and Spanish words (cognates) were produced in random order. Data and Analysis: The study examined the acoustic realization of Spanish and Catalan unstressed /a/, which surfaces as [a] in Spanish but is reduced to schwa, [ə], in Catalan. The acoustic characteristics of unstressed /a/ were explored across the two languages and the two experimental settings. Findings: Catalan unstressed /a/, which was similarly reduced to schwa in the speech of all participants, became slightly more similar to Spanish unstressed /a/ (i.e., it had a higher first formant) when produced alongside Spanish words (bilingual setting) than when produced in a Catalan unilingual setting. There were no effects of linguistic experience, and the effects of setting did not interact with experience. Originality: Very few studies have reported effects of dynamic cross-linguistic interference in phonetic production, and even fewer have reported them with a phonetic variable resulting from a language-specific phonological process (unstressed vowel reduction) rather than a phonemic contrast. Implications: These findings suggest that cross-linguistic interaction is dynamic and modulated by language activation, and that an absence of dominance effects does not necessarily entail an absence of online cross-linguistic phonetic influence.
\end{abstract}




\section{INTRODUCTION}

Bilinguals often differ from monolinguals in their pronunciation, and many attribute such differences to cross-linguistic interactions between bilinguals' first- and second-language phonologies (Best \& Tyler, 2007; Flege, 1995, 2007; Flege, Schirru, \& MacKay, 2003; Simonet, 2016; Van Leussen \& Escudero, 2015). Grosjean (2011) distinguishes two types of cross-linguistic influence, transfer and interference. Transfer is the result of cross-linguistic interactions between long-term memory representations-influence at the abstract level of grammatical competence. Interference, on the other hand, is the result of interactions between representations that are simultaneously activated in working-memory_real-time influence taking place during online speech regulation. For instance, Spanish-dominant Catalan/Spanish bilinguals are known to merge the Catalan vowels /o/ and /o/ in their production (Simonet, 2011); this suggests that, in this population, the two categories are merged into a single phoneme in their grammar and mental lexicon. Thus, such bilinguals appear to have merged a minimal pair such as /os/ 'bear' and /os/ 'bone' into a single phonolexical representation linked to two separate meanings. This is arguably a consequence of Spanish-to-Catalan transfer, since Spanish has only /o/. On the other hand, Catalan-dominant bilinguals who possess two separate phonological representations of the Catalan vowels /o/ and / $/$ in their grammar may produce these vowels as more like Spanish /o/ in situations in which they move back and forth between productions of Spanish and Catalan materials, such as code-switching scenarios (Simonet, 2014). Thus, such bilinguals may experience a temporary, dynamic impact of the activation (in working memory) of Spanish phonology on their Catalan productions, an effect of interference.

The issue we investigate in this study is the extent to which bilingual language modes modulate bilinguals' speech production patterns (Grosjean, 1985, 1989, 1998a, 1998b). We analyze the pronunciation patterns of bilinguals in two settings, one in which they produce words in one language and one in which, in random order, they produce words in their two languages. Studies have suggested that tasks that require speakers to produce materials in their two languages (Amengual, 2018; Simonet, 2014) or to switch rapidly between one language and the other (Goldrick, Runnqvist, \& Costa, 2014; Olson, 2013,2016 ) yield a measurable increase in cross-linguistic phonetic convergence. Here, we pursue this issue further and revisit this paradigm.

\section{Review of the literature}

This study explores the impact of two important factors thought to modulate pronunciation habits in bilinguals. One such factor is language dominance, the second is language modes. While the effects of bilingual language dominance have been the object of numerous phonetic investigations, our understanding of the role of bilingual language modes on pronunciation remains superficial. Many people who speak two languages, and especially those who learned them when they were children, demonstrate a high level of competency in both of them. Most bilinguals, however, have a stronger or dominant language (Cutler, Mehler, Norris, \& Segui, 1989; Flege, MacKay, \& Piske, 2002; Grosjean, 1989). In and of itself, language dominance can only be assessed by means of psycholinguistic tasks (Dunn \& Fox Tree, 2009), but the evidence suggests that dominance is typically the by-product of experience, determined by factors such as age of 
acquisition and daily language use (Birdsong, 2014; Birdsong, Gertken, \& Amengual, 2012; Dunn \& Fox Tree, 2009; Flege et al., 2002).

The scholarship on a particular bilingual population, the Catalan/Spanish bilingual community of Spain, has been instrumental in solidifying the evidence for the existence of cross-linguistic transfer of phonological features in bilinguals and the role of age of acquisition (or dominance) in such transfer (Bosch \& Ramon-Casas, 2011; Mora \& Nadeu, 2012; Navarra, Sebastián-Gallés, \& Soto-Faraco, 2005; Pallier, Bosch, \& Sebastián-Gallés, 1997; Pallier, Colomé, \& Sebastián-Gallés, 2001; Sebastián-Gallés \& Soto-Faraco, 1999). The present study is concerned with the Catalan/Spanish bilingual community on the island of Majorca, Spain. Most research on this particular population centers around the production, perception, and lexical processing of Catalan phonemic contrasts that have no Spanish parallel (Amengual, 2016a, 2016b, 2016c; Ramírez \& Simonet, 2018; Simonet, 2011, 2014). The findings suggest that experience is a strong determinant of linguistic behavior. These studies find that Catalan/Spanish bilinguals who were exposed to Spanish earlier than to Catalan (even as children), who speak mostly Spanish with relatives, and who stick to mostly Spanish-speaking networks, although they may be very proficient in Catalan, tend to demonstrate a reduction in their discrimination (both in perception and in production) of the members of key Catalan phonemic contrasts. The most common interpretation is that the Spanish sound system of such bilinguals is stronger than their Catalan sound system.

According to some, bilinguals store their two sound systems in a common representational network, and the sounds of their dominant language exert a strong influence on the sounds of their other language (Simonet, 2016). Alternatively, it could be that people who learned Spanish before they learned Catalan experience difficulties with Catalan phonemic contrasts as a result of having been exposed to such contrasts only after the offset of a sensitive period of optimal acquisition (Pallier et al., 1997;

Sebastián-Gallés \& Soto-Faraco, 1999). Whatever the etiology of the facts, the effects of language dominance on the linguistic performance of Catalan/Spanish bilinguals is clear.

The second factor we investigate is bilingual language modes, a term that refers to the state of activation of the two systems of a bilingual at a given point in time (Grosjean, 1985, 1989, 1998a, 1998b). According to Grosjean (1985), degrees of activation are determined by psychosocial and linguistic factors modulated in turn by communicative contexts. Bilinguals find themselves in unilingual mode when a situation requires the use of one language whereas they are in bilingual mode when a situation induces the simultaneous use of two languages, such as in a conversation between two bilinguals who share their two languages. Rather than a set of discrete language modes, linguistic co-activation is likely to be a spectrum.

Relative to inter-individual factors, such as dominance, little is known about the intra-individual factors, such as language modes, that can drive cross-linguistic interactions. The studies that have investigated the effects of language modes on pronunciation have done so from two perspectives, code-switching and experimental language-switching. Code-switching is defined as the production of two (or more) languages within a given utterance (Myers-Scotton, 1997), and phonetic studies have assessed whether code-switched sentences lead to enhanced cross-linguistic influence relative to unilingual sentences or whether at (or before) the point of switch there is an increase of cross-linguistic influence (Antoniou, Best, Tyler, \& Kroos, 2010, 2011; Balukas \& Koops, 2015; Bullock, Toribio, González, \& Dalola, 2006; Fricke, Kroll, \& 
Dussias, 2016; González, 2012; Grosjean \& Miller, 1994). While early studies on code-switching did not find it to modulate pronunciation (Grosjean \& Miller, 1994), more recent studies have found such an effect (Antoniou et al., 2011; Balukas \& Koops, 2015; Bullock et al., 2006; Fricke et al., 2016; González, 2012). The research suggests that code-switching, which presumably leads to simultaneous language co-activation, triggers an enhancement of cross-linguistic phonetic convergence.

Other studies have examined the role of experimental language-switching tasks (Goldrick et al., 2014; Olson, 2013) or have manipulated overall language context (Olson, 2013; Simonet, 2014). Unlike code-switching, these tasks do not lead to articulatory planning across languages (cf. Fricke et al., 2016 on planning). In these studies, bilinguals switch randomly between trials that prompt them to produce words in either of their two languages. The acoustics of the speakers' productions in switch trials (i.e., trials that entail a language switch relative to the preceding one) are contrasted with those in stay trials. The results to date are somewhat mixed (Goldrick et al., 2014; Olson, 2013). Goldrick et al. (2014) found increased cross-linguistic phonetic convergence in switch trials relative to stay trials, whereas Olson (2013) found such an increase only in experimental blocks in which such trials were the exception rather than the norm.

Simonet (2014) investigated the effects of bilingual language modes on the phonetic productions of Majorcan Catalan/Spanish bilinguals. In the study, there were two experimental settings, a unilingual Catalan recording session and a bilingual Catalan/Spanish session. The study analyzed the acoustics of the two Catalan mid-back vowels, /o/ and /o/, and compared them with those of Spanish /o/. The procedures in Goldrick et al. (2014) and Olson (2013), on the one hand, and Simonet (Simonet, 2014), on the other, differ in two important ways. Firstly, Simonet did not analyze any effects of switching (switch $v s$. stay trials); secondly, Simonet's speakers participated in a delayed repetition task rather than in a picture-naming task. Simonet (2014) compared the acoustics of key Catalan sounds across the two recording sessions. It was found that, relative to the unilingual setting, the bilingual setting led to an enhancement of cross-linguistic phonetic convergence. This was the case across profiles of language dominance-both Catalan- and Spanish-dominant bilinguals demonstrated the effect.

The present study investigates a phonological process of Catalan, stress-induced vowel reduction. Phonological vowel reduction leads to a decrease in the number of vowel categories that can appear in unstressed position relative to those in stressed position. Catalan displays a set of categorical vowel alternations conditioned by stress; Spanish does not. Both languages display some degree of stress-induced undershoot (Nadeu, 2014). Majorcan Catalan has eight phonemic vowels, all of which are manifested in stressed position, /i e $\varepsilon$ a $\odot \mathrm{o} \mathrm{u} /$. In an unstressed position, only four vowel categories

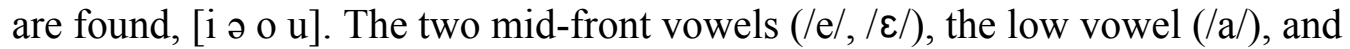
mid-central vowel $(/ \partial /)$ merge to schwa in unstressed syllables. The alternation we explore here is the one that affects /a/. This phoneme is pronounced [a] in stressed position and [ə] in unstressed position: the first vowel in casa 'house' is [a], as it is stressed, but when a suffix displaces the stress from the root, as in caseta 'little house,' this vowel becomes [ə] $(c[\mathrm{a}] s a \sim c[\partial]$ seta $)$. In contrast, Spanish has five vowel phonemes, /i e a o $\mathrm{u} /$, and these vowels do not alternate as a function of lexical stress. The first vowel in both casa 'house' and casita 'little house' is pronounced as [a], even though these words differ in their stress configuration, as they do in their Catalan equivalents. 


\section{The present study}

We designed a phonetic experiment with the goal of addressing whether language dominance and language modes impact bilinguals' pronunciation habits. In particular, we analyzed the acoustic envelope of Catalan and Spanish unstressed /a/ as produced by early Catalan/Spanish bilinguals from the island of Majorca. The crucial experimental manipulation was that speakers participated in two sessions. In the first session, they produced only Catalan materials; in the second session, they produced materials in their two languages. Our study replicates the design in Simonet (2014). Here, we focus on a new phonetic variable, thus extending our current knowledge to an aspect of pronunciation that has received very little attention, unstressed vowel reduction. We investigate only one of the vowel reduction processes of Majorcan Catalan, that affecting /a/, as a proxy for stress-induced phonological processes in general. Our study is original in that it explores a phonological process rather than a phonemic contrast - phonemic contrasts have received most of the scientific attention to date.

\section{METHOD}

\section{Participants}

Our participants were Catalan/Spanish bilinguals born and raised on the island of Majorca, Spain. They were raised either in Spanish- or Catalan-speaking homes, and learned their second language as children, in the community. Many more women (44) than men (15) volunteered to participate. Due to a combination of sociophonetic and biophysical factors, gender is a determinant of the acoustic envelope of vowels (Diehl, Lindblom, Hoemeke, \& Fahey, 1996; Simpson \& Ericsdotter, 2007; Traunmüller, 1984). Since our sample was unbalanced, we focused on the data of the women volunteers.

The experiment required that speakers participate in two sessions. Only 35 of the 44 female volunteers returned for the second session. Five of the 35 remaining volunteers were excluded due to other reasons, such as suffering from nasal congestion at the time of testing. The present study focuses on the remaining 30 volunteers, all of whom were in their early twenties at the time.

The participants responded to a language questionnaire, the Bilingual Language Profile (BLP) (Birdsong et al., 2012). Ten of the 30 participants were assigned to the Catalan-dominant group (G1). The remaining 20 participants, all of them dominant in Spanish (according to the BLP), were divided into two groups as a function of their dominance scores. One group comprised the 10 volunteers who, dominant in Spanish, were closer to being "balanced" bilinguals (G2). The remaining volunteers were assigned to a third group (G3) comprising the 10 most extremely Spanish-dominant bilinguals. This method resulted in three groups of 10 participants each.

All speakers considered themselves very proficient in both languages, and, according to the BLP, they differed only slightly in their attitudes towards their languages. Most of the weight of the difference among the three groups was concentrated, not on their self-assessed proficiency or attitudes, but on their language history (e.g., the order of exposure to each language) and their patterns of daily language usage as adults. 


\section{Materials}

We selected seven disyllabic cognates (and homographs): cala 'cove,' pala 'dustpan,' bala 'bale,' sala 'hall,' tala 'logging,' gala 'gala, ball,' mala 'bad.' Due to a process of stress-induced vowel reduction that operates in Catalan but not in Spanish, the word-final vowel is pronounced [ə] in Catalan and [a] in Spanish. Only one segment from each word was analyzed in our study, the word-final unstressed vowel. The lateral consonant preceding the target vowel may differ in velarization degree across Spanish and Catalan (Simonet, 2010, 2015). Nevertheless, note that the crucial comparison in this study concerns the Catalan productions across the two experimental sessions - this controls for any potential effects of phonetic context on vowel acoustics.

The words were specifically selected to make the cross-linguistic materials as similar as possible. There is ample evidence attesting to the fact that cognates are linked in special ways in the bilingual lexicon. For instance, cognates enhance the phonetic similarities of sound categories linked across languages (Amengual, 2012, 2016a). Our question is whether, beyond any effects induced by cognate status (not relevant here), there are any effects of language mode.

The target words appeared in language-consistent carrier phrases, which varied in their lexical content. Sample carrier phrases are: Sa bala de palla (Catalan), and La bala de paja (Spanish) 'The bale of hay.' There were 85 filler phrases of similar length, 40 in Catalan and 45 in Spanish.

\section{Design and auditory stimuli}

The chosen experimental procedure was an adaptation of the delayed repetition technique (e.g., Guion, 2003). The volunteers were instructed to listen to each phrase in its entirety and only then produce an iteration of their own. Auditory models and participants' repetitions did not overlap in time. Some degree of phonetic imitation is expected, but note that speakers shadowed the same Catalan sound files in both experimental sessions (unilingual, bilingual), rendering any imitation effects irrelevant for our purposes.

While the two experimental settings were designed to manipulate the presence ( $v s$. absence) of Spanish during the production of Catalan phrases, it is unlikely that the first setting was successful in completely inhibiting Spanish. The fact is that both sessions may trigger a certain degree of co-activation of Spanish because both the volunteers and the experimenter are bilingual. Nevertheless, based on the linguistic composition of the materials, we assume that one of the two sessions was more bilingual than the other (Amengual, 2018; Olson, 2013, 2016; Simonet, 2014). Therefore, our design compares degrees of cross-linguistic co-activation rather than endpoints of a spectrum.

Six male "talkers" produced the auditory models to be used in the shadowing task: three Catalan-dominant talkers read aloud the Catalan materials, and three Spanish-dominant talkers read aloud the Spanish materials. Bilingual language dominance patterns for the talkers were confirmed with the BLP (Birdsong et al., 2012). The talkers were given a printed list of the materials, in quasi-random order. They read out loud each sentence twice. The second iteration of each phrase, typically more fluent than the first, was selected. Sound files were normalized for intensity.

Table 1 shows the first-formant $(F 1)$ frequencies of Catalan and Spanish unstressed /a/ in the talkers' productions. As the table shows, $F 1$ values were higher in 
Spanish. The Catalan materials' $F 1$ values have a mean of $573 \mathrm{~Hz}$, and the Spanish ones present an average of $676 \mathrm{~Hz}$. The lowest $F 1$ values in both languages are found in the word pala 'dustpan.' This is due to the fact that the target vowel appears before a high-front glide: Sa pala i sa granera (Catalan), and La pala y la escoba (Spanish) 'The dustpan and the broom.' Due to coarticulation, the glide raises the $F 1$ of the target vowel in both languages. In fact, three talkers seem to apply a vowel coalescence rule. If this item is taken out, there is very little cross-linguistic overlap: Catalan (range $=523-653$ $\mathrm{Hz}$ ), Spanish (range $=641-726 \mathrm{~Hz}$ ).

Table 1. Vowel height $(F 1 \mathrm{in} \mathrm{Hz})$ of the target vowel in the auditory models. There were seven Catalan/Spanish cognates, and each was produced by three male talkers.

\begin{tabular}{ccccccccc}
\hline & & \multicolumn{7}{c}{ Lexical item } \\
\cline { 3 - 8 } Lang. & Talker & bala & cala & gala & mala & pala & sala & tala \\
\hline \multirow{3}{*}{ Cat. } & T1 & 537 & 533 & 526 & 615 & 433 & 528 & 523 \\
& T2 & 612 & 596 & 598 & 653 & 669 & 617 & 621 \\
& T3 & 594 & 558 & 587 & 618 & 495 & 580 & 539 \\
\hline \multirow{3}{*}{ Span. } & T1 & 701 & 719 & 720 & 723 & 646 & 685 & 712 \\
& T2 & 726 & 715 & 641 & 645 & 452 & 699 & 683 \\
& T3 & 716 & 648 & 687 & 657 & 656 & 711 & 663 \\
\hline
\end{tabular}

\section{Procedure}

Three talkers recorded the auditory models for each of the two languages, and all speakers repeated out loud each of the auditory models. Thus, speakers produced each target word three times, in random order. The experiment was run in Praat (Boersma, 2001). Headphones were used to play the auditory models to the participants. Their productions were recorded with a digital speech recorder (Marantz PMD 660), a head-worn condenser microphone (Audix HT5), and a pre-amplifier (Sound Devices MM-1). The signal was digitized at $44.1 \mathrm{kHz}, 16$-bit quantization.

The participants came to a quiet laboratory on the campus of the University of the Balearic Islands. The entire experiment (questionnaire, recordings) took place there. In the unilingual session, they first responded to the bilingual questionnaire, then listened to (and repeated out loud) the Catalan auditory models. In the bilingual session, the volunteers returned to the same testing room and listened to (and repeated out loud) the Catalan and the Spanish auditory models, in random order. The two sessions were at least 48 hours apart, but could be up to a week apart for some volunteers. Note that the participants shadowed the exact same Catalan auditory stimuli in the two sessions. This should minimize (or even neutralize), rather than enhance, session effects. 
The analyses focused on the first- $(F 1)$ and second-formant $(F 2)$ values of the target vowels. Formant values were extracted from LPC spectra (Burg algorithm) calculated from Gaussian $25 \mathrm{~ms}$ windows in Praat (Boersma, 2001). The procedure computed 5 formants below $5.5 \mathrm{kHz}$. Gaussian windows were extracted from a temporal landmark located $25 \mathrm{~ms}$ after the offset of $/ 1 /$. Acoustic landmarks were placed manually. Values were converted to Mel, a psychoacoustic scale (Stevens, Volkmann, \& Newman, 1937).

The factor dominance group has three discrete levels (G1, G2, G3); numbers become progressively larger as dominance in Spanish increases. Rather than a continuous predictor, we chose to categorize dominance in three discrete groups to allow for a direct comparison of our findings with those of Simonet (2014). We operationalized the factor experimental condition to have three levels as well: Catalan words in the unilingual session (C1), Catalan words in the bilingual session (C2), and Spanish words in the bilingual session (C3). It is important to highlight that the factor experimental condition is a within-items and within-subjects factor. This requires some explanation. We decided to pair the cognates as if they were "the same" lexical item. For instance, the word bala 'bale' appears as a Catalan word in both $\mathrm{C} 1$ and $\mathrm{C} 2$ (the same Catalan materials appeared in both), and a Spanish word in C3. This allows us to reduce two factors (session, language) to a single three-level factor (condition). In sum, C1 and C2 would have been pronounced as imitations to the same Catalan auditory models whereas $\mathrm{C} 3$ consists of imitations to Spanish stimuli.

In the unilingual session, participants produced a total of 21 Catalan target phrases (and 120 fillers): 7 target words $\times 3$ iterations (auditory models). We collected 630 target tokens in the Catalan unilingual session: 21 tokens $\times 30$ speakers. Of these, 25 had to be excluded due to recording errors, including production of the wrong word and coughing. In the bilingual session, participants produced the same 630 Catalan tokens (plus fillers) together with the Spanish tokens (and the Spanish fillers). There were seven Spanish target words, each produced by three different talkers: 7 words $\times 3$ iterations (auditory models). This led to a total of 630 Spanish targets ( 21 tokens $\times 30$ participants) plus 135 fillers. Together, the Spanish and Catalan target phrases recorded in the bilingual session amounted to 1260 . Of these, 32 were excluded due to recording errors, resulting in a total of 1228 tokens submitted to acoustic scrutiny: 609 Catalan tokens, 619 Spanish tokens. Note that the target words were randomly interspersed among a large number of fillers; speakers, thus, did not rapidly switch from a Spanish target word to a Catalan target word or vice versa, at least not consistently.

Each of the 30 speakers contributed a theoretical ceiling of 63 observations to the final dataset: 21 Catalan tokens in the unilingual session $(\mathrm{C} 1)+21$ Catalan tokens in the bilingual session $(\mathrm{C} 2)+21$ Spanish tokens in the bilingual session $(\mathrm{C} 2)$. This resulted in a total of 1833 observations. The target formant values were explored with a series of analyses of variance, consisting of both by-subjects and by-items analyses. The by-subjects analyses had a between-subjects factor (group) and a within-subjects factor (condition). The by-items analyses had two within-items factors, group and condition. The alpha criterion was set at 0.05 , and we only considered significant those effects that were found to be so in both the by-subjects and by-items analyses. Inferential statistics 
were run in $R$ (R Development Core Team, 2016). The $R$ packages used to run analyses and find effect sizes were $e z$ (Lawrence, 2016) and effsize (Torchiano, 2017).

\section{RESULTS}

Here we report on the analyses of vowel fronting $(F 2)$ and height $(F 1)$, in this order. Regarding fronting $(F 2)$, a by-subjects mixed-design ANOVA failed to yield any significant effects; the by-items repeated measures ANOVA yielded marginally significant effects of dominance group $\left(F(2,12)=7.193, p<0.01, \eta^{2}=0.042\right)$, but no effects of condition, and no interaction between the two. Since no main effect (or interaction) appeared in both the by-subjects and the by-items analyses, we dismiss the marginal group effects produced by the by-items analysis. It appears, therefore, that Catalan and Spanish unstressed /a/ do not differ significantly in terms of fronting $(F 2)$.

Table 2. Descriptive statistics (means and standard deviations) for $F 1$ (Mel) shown as a function of dominance group (G1, G2, G3) and experimental condition (C1 [Catalan in unilingual setting], C2 [Catalan in bilingual setting], C3 [Spanish in bilingual setting]).

\begin{tabular}{cccc}
\hline \multirow{3}{*}{ Condition } & \multicolumn{3}{c}{ Dominance Group } \\
\cline { 2 - 4 } & G1 & G2 & G3 \\
\hline C1 & $406(26)$ & $404(22)$ & $421(30)$ \\
C2 & $414(26)$ & $411(23)$ & $426(29)$ \\
C3 & $485(25)$ & $486(22)$ & $489(24)$ \\
\hline
\end{tabular}

Table 2 shows the descriptive statistics for $F 1$, organized as a function of condition (C1, C2, C3) and dominance group (G1, G2, G3). The by-subjects mixed-design ANOVA yielded significant effects of condition $(F(2,54)=325.92, p<$ $\left.0.001, \eta^{2}=0.671\right)$, but no effects of dominance group, and no interaction between the two factors. The by-items repeated measures ANOVA revealed significant effects of condition $\left(F(2,12)=223.24, p<0.001, \eta^{2}=0.775\right)$ and of dominance group $(F(2,12)=25.958, p<$ $\left.0.001, \eta^{2}=0.077\right)$, as well as a significant interaction between the two $(F(4,24)=5.326, p$ $\left.<0.01, \eta^{2}=0.023\right)$. The only main effect obtained in both the by-subjects and the by-items analyses are the effects of experimental condition. It is not surprising to find effects of condition because we are comparing Catalan with Spanish. It could simply be that our speakers produce Catalan and Spanish unstressed /a/ as different acoustic categories, which is expected. The question with the highest theoretical relevance is whether there are differences between conditions $\mathrm{C} 1$ and $\mathrm{C} 2$, both of which consist of productions of the same Catalan materials (as imitations to the same auditory models).

In order to address this question, we conducted a series of follow-up analyses in which C3 (Spanish) was excluded. A by-subjects mixed-design ANOVA with condition $(\mathrm{C} 1, \mathrm{C} 2)$ and dominance group $(\mathrm{G} 1, \mathrm{G} 2, \mathrm{G} 3)$ as predictors, and $F 1$ as the dependent variable, revealed significant effects of condition $\left(F(1,27)=13.432, p=0.001, \eta^{2}=\right.$ $0.018)$, but neither dominance group nor an interaction were found to be significant. A by-items repeated measures ANOVA found significant effects of condition $(F(1,6)=$ 
$\left.16.192, p<0.01, \eta^{2}=0.024\right)$ and of dominance $\operatorname{group}\left(F(2,12)=31.245, p<0.001, \eta^{2}=\right.$ $0.113)$, but no interaction.

Note that both the by-subjects and the by-items analyses coincide in yielding significant effects of experimental condition. In particular, when Catalan unstressed /a/, which is effectively reduced to schwa, is produced in a bilingual setting it has, on average, a higher $F 1$ than when it is produced in a unilingual session - it moves towards the direction of Spanish [a]. The difference is acoustically small $(-6.75 \mathrm{Mel})$, and the statistical effect is only of medium size (Cohen's $d=-0.686 ; 95 \%$ c.i. $[-10.43,-3.08]$ ), but it is significant nevertheless $(t(29)=-3.76, \mathrm{p}<0.001)$ and in the predicted direction. The probability that a value sampled at random from the $\mathrm{C} 1$ distribution is greater than a value sampled at random from the C2 distribution is 0.428 (42.8\%) (McGraw \& Wong, 1992).

\section{DISCUSSION}

Firstly, the Catalan/Spanish bilinguals in the study, regardless of their dominance profile, pronounced Catalan unstressed /a/ as schwa and Spanish unstressed /a/ as [a]. There were no consistent dominance-induced differences across speakers in terms of their pronunciation of these sounds. Secondly, unstressed Catalan /a/ produced in a bilingual setting was found to have, on average, a slightly higher first formant than those produced in a unilingual setting. This effectively makes unstressed Catalan schwa acoustically more similar to its Spanish counterpart, [a]. The findings suggest that, when bilingual speakers produce words in two languages ( $v s$. in one language), cross-linguistic phonetic category assimilations become stronger (Amengual, 2018; Antoniou et al., 2011; Goldrick et al., 2014; Grosjean, 2011; Olson, 2013, 2016; Simonet, 2014).

The most important finding of the present study was that Catalan unstressed /a/ converged towards Spanish unstressed /a/ when found in an experimental setting in which both Catalan and Spanish words were being produced. This finding demonstrates effects of language modes in bilingual pronunciation. People who speak two languages fluctuate between situations where they use both of their languages and situations where they use only one, and such fluctuations drive language co-activation levels (Grosjean, 1985, 1998b). Relative to unilingual settings, situations of increased cross-linguistic co-activation seem to lead to an enhancement of phonetic convergence in bilingual speech production (Amengual, 2018; Goldrick et al., 2014; Olson, 2013; Simonet, 2014). Since we found no consistent effects of language dominance, we surmise that increased cross-linguistic co-activation may even bring to light intra-individual cross-linguistic influences that inter-individual comparisons do not reveal (Grosjean, 2011).

Our main finding replicates the one in Simonet (2014), who found that, in the speech of Catalan/Spanish bilinguals, both Catalan /o/ and /o/ become more like Spanish $/ \mathrm{o} /$ in a bilingual (relative to a unilingual) setting and that this effect does not interact with language dominance. Note that the bilingual session was much longer than the unilingual one because it comprised many more phrases. The pronunciation differences between the unilingual and bilingual sessions could be attributed to exhaustion, leading to more reduced pronunciation patterns in the longer session. The effects of exhaustion, however, would arguably lower vowel height across categories (or would centralize them). Interestingly, whereas, relative to the unilingual setting, the bilingual condition yielded a raising of Catalan $/ \mathrm{o} /$ and $/ \mathrm{o} /$, the present study has found that, relative to the unilingual 
setting, the bilingual condition led to a lowering of unstressed Catalan /a/. The findings can only be attributed to enhanced cross-linguistic convergence.

The lack of dominance effects, though surprising to some extent, was not entirely unexpected. In a study comparable to the present one, Amengual and Simonet (n.d.) found that a group of early Catalan/Spanish bilinguals manifested robust effects of language dominance in their production of the Catalan mid vowel contrasts, $/ \varepsilon /-/ \mathrm{e} /$ and $/ \mathrm{o} / / \mathrm{o} /$, but not in their reduction of Catalan unstressed /a/. In the context of the larger literature on bilingual pronunciation, this is not a typical finding. All prior studies on the bilingual population that concerns us here had documented differences in speech behavior as a function of language dominance. Such effects had been found for many variables, including vowel and consonant contrasts specific to C atalan (Amengual, 2016b, 2016c; Ramírez \& Simonet, 2018; Simonet, 2011). For some reason, Spanish-dominant bilinguals find the Catalan mid vowels (and other sounds of Catalan) more "difficult" to master than the Catalan unstressed vowel reduction rule, at least the rule that applies to /a/. With a new sample recruited from the same population, the present study replicated the null effect already reported in Amengual and Simonet (n.d.). Catalan unstressed vowel reduction (or Catalan unstressed schwa) is not particularly challenging for Spanish-dominant bilinguals.

The lack of dominance effects in our production experiment, as well as in Amengual and Simonet (n.d.), suggest that the phonological knowledge of Catalan/Spanish bilinguals includes a system with (Catalan) and a system without (Spanish) phonological unstressed vowel reduction. Catalan/Spanish bilinguals restrict the application of unstressed vowel reduction to only one of their two languages, Catalan; that is, when they produce Catalan words, these bilinguals apply a process of unstressed vowel reduction; when they produce Spanish words, they do not. In terms of unstressed vowel reduction, we found no evidence of transfer, in the sense of cross-linguistic influence between long-term phonological representations, between the phonologies of Catalan and Spanish. On the other hand, the existence of (dynamic) interference effects, revealed by language-mode manipulations, suggest that the two systems are not truly independent from each other. While, perhaps, the two systems do not interact in long-term memory, it appears that they do interact in working-memory. In the terminology of Grosjean (2011), we seem to have evidence of (phonetical) interference in the absence of (phonological) transfer. In the words of Goldrick et al. (2014, p. 1034), our data support the idea that "variations in the relative activation of target versus nontarget representations within lexical access can influence phonetic processing." In our design, Spanish phonology was presumably more activated in the bilingual setting than in the unilingual setting. We found that the relative co-activation of the nontarget language influences pronunciation patterns in the target language. Our findings suggest that "the greater activation of nontarget language representations for cognates will cascade to phonetic processes, enhancing the degree to which phonetic properties of the nontarget language intrude during production" (Goldrick et al., 2014, p. 1035).

Prior to the present study, language mode effects had been revealed in cases in which cross-linguistic interactions had previously been demonstrated in other ways (Antoniou et al., 2011; Goldrick et al., 2014; Olson, 2013, 2016). For instance, it appears that, in Spanish-English bilinguals, the voice onset times of utterance-initial stops interact across their two languages - e.g., English voiceless stops are less (and Spanish ones are more) aspirated in bilinguals' productions than in those of monolinguals (Flege \& 
Eefting, 1987; Schmidt \& Flege, 1996; Williams, 1977). This suggests cross-linguistic phonetic convergence between similar categories in the bilinguals. Note that such convergence has been postulated from the findings of between-speaker comparisons. Three studies have additionally demonstrated that bilingual context and rapid language switching lead to enhanced phonetic convergence in Spanish-English bilinguals' productions of stop consonants (Goldrick et al., 2014; Olson, 2013, 2016). In Grosjean's (2011) view, interference is the result of a cross-linguistic interaction taking place in working-memory, between the elements of two languages that are simultaneously co-activated. Transfer is the result of interactions between long-term memory representations. While the effects of transfer may be revealed by inter-speaker comparisons, those of interference may only be revealed by intra-speaker comparisons. In terms of the cross-linguistic influences affecting the nature of stops in Spanish-English bilinguals, studies have demonstrated the existence of both transfer (Flege \& Eefting, 1987; Schmidt \& Flege, 1996; Williams, 1977) and interference (Goldrick et al., 2014; Olson, 2013, 2016). To conclude, we believe we have found evidence of cross-linguistic interference for a feature for which we found no evidence of transfer.

\section{CONCLUSION}

A group of Catalan/Spanish bilingual women, classified as a function of whether they were dominant in Catalan or Spanish, participated in a phonetic experiment consisting of two production sessions, a unilingual Catalan recording session and a bilingual recording session. The study analyzed the acoustics of word-final, unstressed /a/. In Catalan, a phonological rule reduces unstressed /a/ to schwa, while in Spanish this vowel is not involved in any phonological alternation and is thus pronounced [a].

The main goal of the present study was to investigate the potential effects of dominance and language modes (or settings) on the production of unstressed Catalan /a/. The results of our experiment demonstrate that increased linguistic co-activation modulated by bilingual language modes leads to an enhancement of cross-linguistic phonetic convergence. In the particular case we investigated here, our results suggested the existence of cross-linguistic interference for a feature for which we did not find effects of bilingual language dominance. Thus, even though Catalan/Spanish bilinguals seem to be able to switch between a system with (Catalan) and a system without (Spanish) phonological stress-induced vowel reduction, one cannot say that these two phonological systems are entirely independent from each other- the two systems interact in working-memory, when both are activated. We found evidence of interference for a phonological feature for which we found no evidence of transfer (Grosjean, 2011).

\section{REFERENCES}

Amengual, M. (2012). Interlingual influence in bilingual speech: Cognate status effect in a continuum of bilingualism. Bilingualism: Language and Cognition, 15, 517-530.

Amengual, M. (2016a). Cross-linguistic influence in the bilingual mental lexicon: Evidence of cognate effects in the phonetic production and processing of a vowel contrast. Frontiers in Psychology, 7, 617.

Amengual, M. (2016b). The perception and production of language-specific mid-vowel contrasts: Shifting the focus to the bilingual individual in early language input 
conditions. International Journal of Bilingualism, 20, 133-152.

Amengual, M. (2016c). The perception of language-specific phonetic categories does not guarantee accurate phonological representations in the lexicon of early bilinguals. Applied Psycholinguistics, 37, 1221-1251.

Amengual, M. (2018). Asymmetrical interlingual influence in the production of Spanish and English laterals as a result of competing activation in bilingual language processing. Journal of Phonetics, 69, 12-28.

Amengual, M., \& Simonet, M. (n.d.). Language dominance does not always predict cross-linguistic interactions in bilingual speech production. Submitted.

Antoniou, M., Best, C. T., Tyler, M. D., \& Kroos, C. (2010). Language context elicits native-like stop voicing in early bilinguals' productions in both L1 and L2. Journal of Phonetics, 38, 640-653.

Antoniou, M., Best, C. T., Tyler, M. D., \& Kroos, C. (2011). Inter-language interference in VOT production by L2-dominant bilinguals: Asymmetries in phonetic code-switching. Journal of Phonetics, 39, 558-570.

Balukas, C., \& Koops, C. (2015). Spanish-English bilingual voice onset time in spontaneous code-switching. International Journal of Bilingualism, 19, 423-443.

Best, C. T., \& Tyler, M. D. (2007). Nonnative and second-language speech perception: Commonalities and complementarities. In O.-S. Bohn \& M. Munro (Eds.), Language experience in second language speech learning: In honor of James Emil Flege (pp. 13-34). Amsterdam, The Netherlands: John Benjamins.

Birdsong, D. (2014). Dominance and age in bilingualism. Applied Linguistics, 35, 374-392.

Birdsong, D., Gertken, L. M., \& Amengual, M. (2012). Bilingual language profile: An easy-to-use instrument to assess bilingualism. COERLL, University of Texas at Austin.

Boersma, P. (2001). Praat, a system for doing phonetics by computer. Glot International, $5,341-345$.

Bosch, L., \& Ramon-Casas, M. (2011). Variability in vowel production by bilingual speakers: Can input properties hinder the early stabilization of contrastive categories? Journal of Phonetics, 39, 514-526.

Bullock, B., Toribio, A. J., González, V., \& Dalola, A. (2006). Language dominance and performance outcomes in bilingual pronunciation. In M. Grantham O'Brien, C. Shea, \& J. Archibald (Eds.) (pp. 9-16). Presented at the Proceedings of the 8th Generative Approaches to Second Language Acquisition Conference, Somerville, MA: Cascadilla Proceedings Project.

Cutler, A., Mehler, J., Norris, D., \& Segui, J. (1989). Limits on bilingualism. Nature, 340, 229-230.

Diehl, R. L., Lindblom, B., Hoemeke, K. A., \& Fahey, R. P. (1996). On explaining certain male-female differences in the phonetic realization of vowel categories. Journal of Phonetics, 24, 187-208.

Dunn, A. L., \& Fox Tree, J. E. (2009). A quick, gradient Bilingual Dominance Scale. Bilingualism , 12, 273-289.

Flege, J. E. (1995). Second language speech learning: Theory, findings, and problems. In W. Strange (Ed.), Speech perception and linguistic experience: Issues in cross-language research (pp. 229-273). Timonium, Maryland: York Press.

Flege, J. E. (2007). Language contact in bilingualism: Phonetic system interactions. In J. 
Cole \& J. I. Hualde (Eds.), Laboratory Phonology 9 (pp. 353-380). Berlin, Germany: Mouton de Gruyter.

Flege, J. E., \& Eefting, W. (1987). Production and perception of English stops by native Spanish speakers. Journal of Phonetics, 15, 67-83.

Flege, J. E., MacKay, I. R. A., \& Piske, T. (2002). Assessing bilingual dominance. Applied Psycholinguistics, 23, 567-598.

Flege, J. E., Schirru, C., \& MacKay, I. R. A. (2003). Interaction between the native and second language phonetic subsystems. Speech Communication, 40, 467-491.

Fricke, M., Kroll, J. F., \& Dussias, P. E. (2016). Phonetic variation in bilingual speech: A lens for studying the production-comprehension link. Journal of Memory and Language, 89, 110-137.

Goldrick, M., Runnqvist, E., \& Costa, A. (2014). Language switching makes pronunciation less nativelike. Psychological Science, 25, 1031-1036.

González, V. (2012). Spanish and English word-initial voiceless stop production in code-switched vs. monolingual structures. Second Language Research, 28, 243-263.

Grosjean, F. (1985). The bilingual as a competent but specific speaker-hearer. Journal of Multilingual \& Multicultural Development, 6, 467-477.

Grosjean, F. (1989). Neurolinguists, beware! The bilingual is not two monolinguals in one person. Brain and Language, 36, 3-15.

Grosjean, F. (1998a). Studying bilinguals: Methodological and conceptual issues. Bilingualism: Language and Cognition, 1, 131-148.

Grosjean, F. (1998b). Transfer and language mode. Bilingualism: Language and Cognition, 1, 175-176.

Grosjean, F. (2011). An attempt to isolate, and then differentiate, transfer and interference. International Journal of Bilingualism, 16, 11-21.

Grosjean, F., \& Miller, J. L. (1994). Going in and out of languages: An example of bilingual flexibility. Psychological Science, 5, 201-206.

Guion, S. G. (2003). The vowel systems of Quichua-Spanish bilinguals. Phonetica, 60, 98-128.

Lawrence, M. A. (2016). Easy analysis and visualization of factorial experiments. Retrieved from https://github.com/mike-lawrence/ez

McGraw, K. O., \& Wong, S. P. (1992). A common language effect size statistic. Psychological Bulletin, 111, 361.

Mora, J. C., \& Nadeu, M. (2012). L2 effects on the perception and production of a native vowel contrast in early bilinguals. International Journal of Bilingualism, 16, 484-500.

Myers-Scotton, C. (1997). Duelling languages: Grammatical structure in codeswitching. Oxford, UK: Oxford University Press (Clarendon Press).

Nadeu, M. (2014). Stress- and speech rate-induced vowel quality variation in Catalan and Spanish. Journal of Phonetics, 46, 1-22.

Navarra, J., Sebastián-Gallés, N., \& Soto-Faraco, S. (2005). The perception of second language sounds in early bilinguals: new evidence from an implicit measure. Journal of Experimental Psychology. Human Perception and Performance, 31, 912.

Olson, D. J. (2013). Bilingual language switching and selection at the phonetic level: Asymmetrical transfer in VOT production. Journal of Phonetics, 41, 407-420.

Olson, D. J. (2016). The role of code-switching and language context in bilingual phonetic transfer. Journal of the International Phonetic Association, 46, 263-285. 
Pallier, C., Bosch, L., \& Sebastián-Gallés, N. (1997). A limit on behavioral plasticity in speech perception. Cognition, 64, B9-B17.

Pallier, C., Colomé, A., \& Sebastián-Gallés, N. (2001). The influence of native-language phonology on lexical access: Exemplar-based versus abstract lexical entries. Psychological Science, 12, 445-449.

Ramírez, M., \& Simonet, M. (2018). Language dominance and the perception of the Majorcan Catalan $/ \mathrm{K} /-/ 3 /$ contrast: Asymmetrical phonological representations. International Journal of Bilingualism, 22, 638-652.

R Development Core Team. (2016). R: A language and environment for statistical computing. Vienna, Austria. Retrieved from http://www.R-project.org/

Schmidt, A. M., \& Flege, J. E. (1996). Speaking rate effects on stops produced by Spanish and English monolinguals and Spanish/English bilinguals. Phonetica, 53, $162-179$.

Sebastián-Gallés, N., \& Soto-Faraco, S. (1999). Online processing of native and non-native phonemic contrasts in early bilinguals. Cognition, 72, 111-123.

Simonet, M. (2010). Dark and clear laterals in Catalan and Spanish: Interaction of phonetic categories in early bilinguals. Journal of Phonetics, 38, 663-678.

Simonet, M. (2011). Production of a Catalan-specific vowel contrast by early Spanish-Catalan bilinguals. Phonetica, 68, 88-110.

Simonet, M. (2014). Phonetic consequences of dynamic cross-linguistic interference in proficient bilinguals. Journal of Phonetics, 43, 26-37.

Simonet, M. (2015). An acoustic study of coarticulatory resistance in "dark" and "light" alveolar laterals. Journal of Phonetics, 52, 138-151.

Simonet, M. (2016). The phonetics and phonology of bilingualism. In Oxford Handbooks Online: Scholarly Research Reviews (pp. 1-25). Oxford, UK: Oxford University Press. https://doi.org/10.1093/oxfordhb/9780199935345.013.72

Simpson, A., \& Ericsdotter, C. (2007). Sex-specific differences in f0 and vowel space. In J. Trouvain \& W. Barry (Eds.), XVIth International Congress of Phonetic Sciences (pp. 933-936). Saarbrücken, Germany.

Stevens, S. S., Volkmann, J., \& Newman, E. B. (1937). A scale for the measurement of the psychological magnitude pitch. The Journal of the Acoustical Society of America, $8,185-190$.

Torchiano, M. (2017). effsize: A collection of functions to compute the standardized effects sizes for experiments (Version 0.7.1). Retrieved from https://github.com/mtorchiano/effsize/

Traunmüller, H. (1984). Articulatory and perceptual factors controlling the age- and sex-conditioned variability in formant frequencies of vowels. Speech Communication, 3, 49-61.

Van Leussen, J.-W., \& Escudero, P. (2015). Learning to perceive and recognize a second language: The L2LP model revised. Frontiers in Psychology, 6, 1-12.

Williams, L. (1977). The perception of stop consonant voicing by Spanish-English bilinguals. Attention, Perception \& Psychophysics, 21, 289-297. 